\title{
Father involvement among Malay Muslims in Malaysia
}

\begin{abstract}
This article reports on findings from a study of 989 fathers of school-going children aged 10 through 16 from intact families in rural and urban areas in Selangor, Malaysia. The study aims to explore the factors that affect father involvement among Malay Muslims. Results indicate that fathers' education, marital quality, and number of children are significantly related to their involvement in children's lives. Fathers' perceptions of their own fathers' involvement when they were young is also positively associated with their involvement with children, supporting the concept of intergenerational fathering in social learning theory. Muslim fathers see financial provisioning, moral teaching, praying, reciting the Quran, and fasting together with children as their religious duties that God entrusts to them to fulfill both world and after-life purposes. However, they cite lack of time and a common wish to be more involved in their children's life.
\end{abstract}

Keyword: Fathering; Father involvement; Intergenerational fathering; Marital satisfaction 